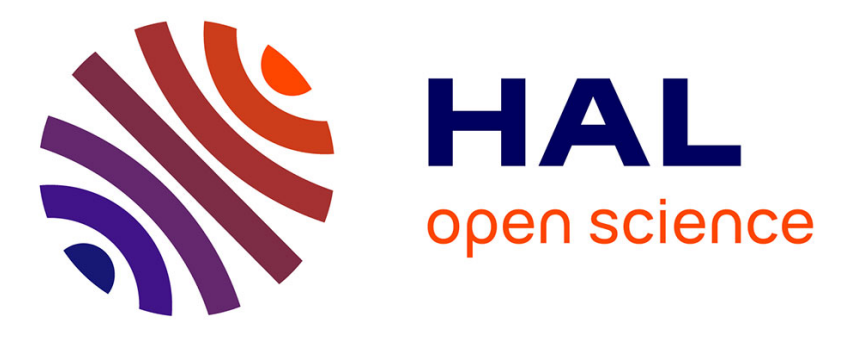

\title{
Comparison of 3D Thermal Equivalent Circuit Architectures of Asynchronous Machines
}

Shinara Utegenova, Raynal Glises, Philippe Désévaux, Frédéric Dubas, Damien Mariotto, Bertrand Truffart

\section{- To cite this version:}

Shinara Utegenova, Raynal Glises, Philippe Désévaux, Frédéric Dubas, Damien Mariotto, et al.. Comparison of 3D Thermal Equivalent Circuit Architectures of Asynchronous Machines. International Conference on Electrical Machines, Sep 2016, Lauzanne, Switzerland. hal-02130747

\section{HAL Id: hal-02130747 \\ https://hal.science/hal-02130747}

Submitted on 16 May 2019

HAL is a multi-disciplinary open access archive for the deposit and dissemination of scientific research documents, whether they are published or not. The documents may come from teaching and research institutions in France or abroad, or from public or private research centers.
L'archive ouverte pluridisciplinaire HAL, est destinée au dépôt et à la diffusion de documents scientifiques de niveau recherche, publiés ou non, émanant des établissements d'enseignement et de recherche français ou étrangers, des laboratoires publics ou privés. 


\title{
Comparison of 3D Thermal Equivalent Circuit Architectures of Asynchronous Machines
}

\author{
Sh. Utegenova, R. Glises, Ph. Desevaux, F. Dubas, D. Mariotto, B. Truffart
}

\begin{abstract}
This paper is dealing with the thermal modeling of high-speed asynchronous machines for helicopter using 3D finite-difference thermal equivalent circuit. The main goal of this work is to choose a thermal equivalent circuit (TEC) structure for a generalized low time cost numerical tool aiming to precisely predict the thermal behavior of high-speed asynchronous machines (example taken from the literature to validate the model: $29 \mathrm{~kW} @ 12 \mathrm{krpm}$ including water cooling jacket) at steady state, taking into account geometry variations of the machine, particularly stator and rotor pole numbers variation.
\end{abstract}

Index Terms -- Electrical machine, thermal equivalent circuit, pole number variation, 3D thermal design

\section{NOMENCLATURE}

TEC Thermal Equivalent Circuit

$\rho \quad$ Node material density.

$c_{p} \quad$ Node material specific heat capacity.

$V \quad$ Node volume.

$G \quad$ Conductances (inverse of thermal resistances).

Temperature.

$t \quad$ Time.

\section{INTRODUCTION}

$\mathrm{N}$ OWEDAYS, the electric propulsion system enters intensely in the aerospace world [1]. The machine technologies are compared in the context of their performances, dimensions and ability to satisfy the specific safety requirements. Once dimension and performance requirements are defined, the thermal design permits to identify the correspondence of the machine to the safety specifications.

In this article, thermal modeling using TEC method for high-speed asynchronous machines for helicopter use is discussed. This well-grounded method [2]-[5] consists in 3D discretization of the induction motor into isothermal volumes linked together with thermal conductances that represent different types of internal thermal transfers [6]. These thermal conductances represent the conduction, convection and radiation phenomenon, as well as the mass flow in the cooling ducts. In this modeling of an asynchronous motor, the radiation phenomenon is neglected because of the relatively low level of reached temperature of such machines, particularly on their external surfaces.

While the variation of the values of the main dimensions does not influence on the calculation architecture, stator and rotor tooth number variation requires a modification of the

This work was supported by Airbus Helicopters in partnership with the University of Bourgogne Franche-Comte (UBFC) and FEMTO-ST Institute (UMR CNRS 6174). whole TEC.

This work is aimed to compare different approaches of TEC architecture strategy, permitting to keep the same equivalent circuit independently of the pole number variation. As a result, a symmetrical simplification stays valid, permitting to keep the minimal number of nodes without reducing the precision of the model with respect to the poles symmetries for rotor and stator.

\section{TEC ARCHITECTURES}

The number of stator and rotor slots varies from one machine configuration to another, and usually it is not the same for rotor and stator as shown in Fig. 1.

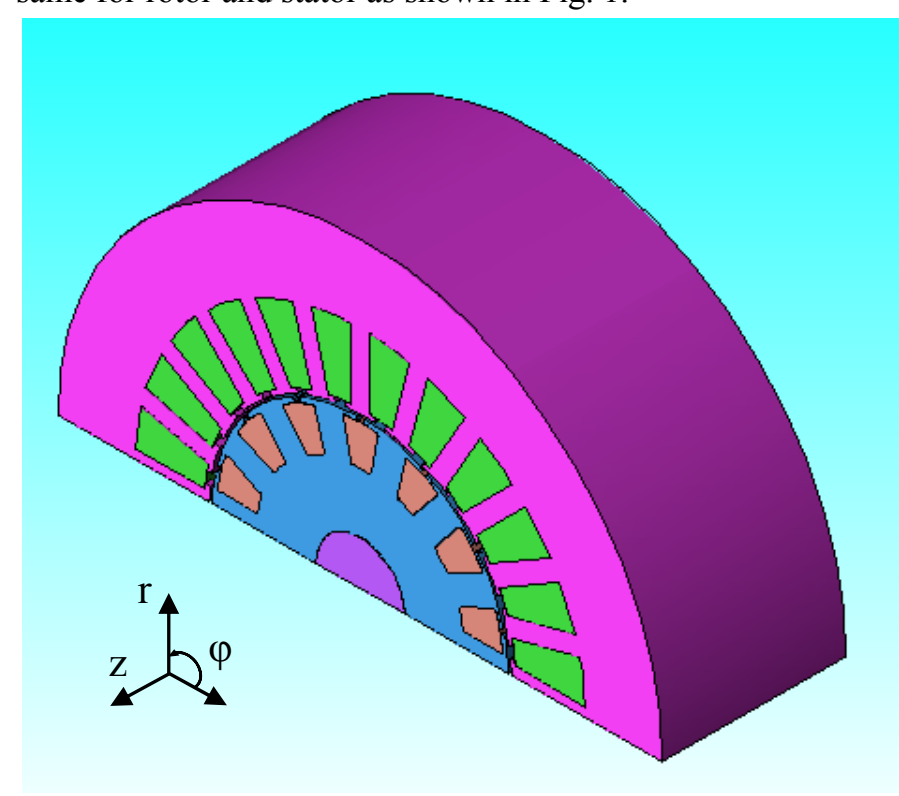

Fig. 1. Machine halved geometry.

Fig. 2 shows that there are thermals resistances in $\varphi$-axis direction of cylindrical coordinate system, which doesn't permit to reduce the thermal resistances circuit in the same way as if it was an electric circuit with parallel paths.

So with the variation of number of slots, the number of $\varphi$ axis thermal resistances varies also, modifying the whole TEC.

Taking into account all the slot numbers leads to increase considerably the number of nodes, so modeling of each machine configuration separately leads to an important time cost.

As a result, a generalized TEC independent on slot number variation couldn't be developed without simplifications.

In this work three different thermal circuit architecture 
strategies are studied. The results obtained with these architectures are compared to experimental test results from the literature in order to examine the accuracy of each one.
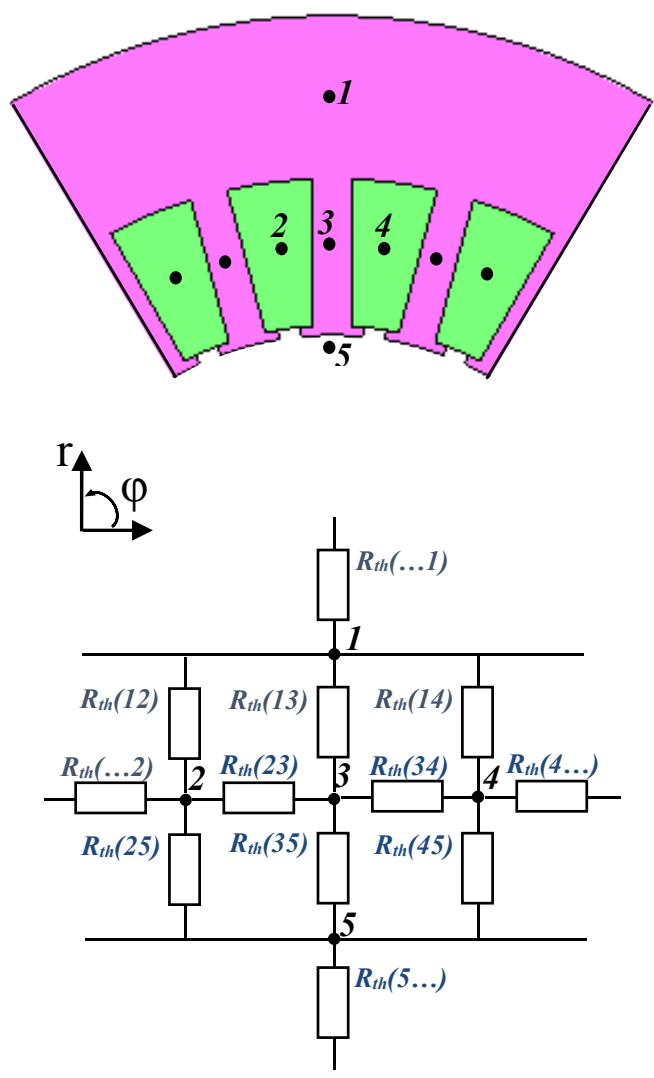

Fig. 2. Part of a thermal resistances circuit.

\section{A. First architecture}

Division of stator and rotor geometries by number of stator and rotor slots respectively may seem to be the most evident and feasible solution, because in that case the number of nodes is the same for no matter what motor geometry, and so the TEC architecture remains constant.

However, as it could be seen in Fig. 3 the pole angle of the stator is rarely the same as the pole angle of the rotor.

So the thermal flux generated in the stator does not correspond to that of the rotor, so the thermal model based on this theory is not accurate.

It seems to be interesting however to propose some simplifications in order to keep this architecture and to compare it with the other approaches.

As one of the proposed simplifications it could be suggested to introduce a coefficient depending on ratio of rotor and stator slot numbers permitting the adjustment of stator and rotor heat fluxes (along the radius) in accordance with chosen rotor or stator pole angle.

This method of TEC construction permits to keep the same circuit for all the machines of this type and to respect the simulation time limits.

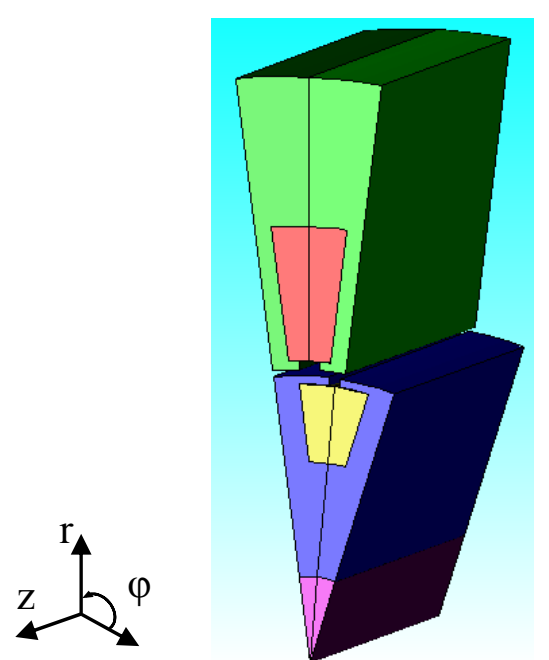

Fig. 3. Stator and rotor geometry divided by number of stator and rotor slot numbers respectively.

\section{B. Second architecture}

As the slots, and as a consequence electrical windings inside the slots, are thermally isolated in the radial and orthoradial directions, the $\varphi$-axis resistances between slots and teeth are high enough so that the heat exchanges in this direction could be neglected. The equivalent resistances taking into account stator and rotor slot numbers variation could be easily calculated without changing number of nodes as shown in Fig. 4.

This simplification leads to introduce an adjustment coefficient permitting to adjust the contact surface among winding, tooth and yoke.

The advantage of this TEC is the fact that it permits to model the whole machine in such a way that thermal flux passing between stator and rotor is appropriate and the number of nodes remains constant, which permits in its turn to use this circuit architecture in a generalized low time cost numerical tool.

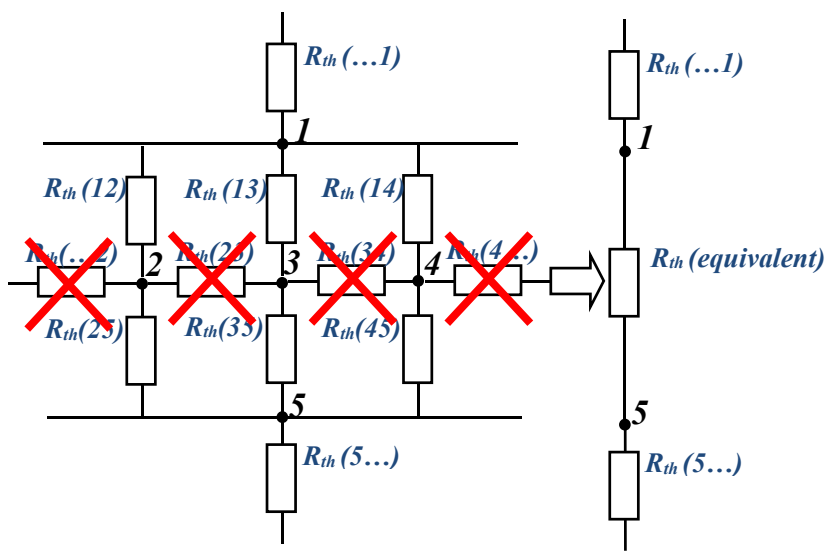

Fig. 4. Equivalent resistance principle.

\section{Third architecture}

The third circuit does not introduce any additional simplifications into the TEC method. In order to compare the two thermal circuit construction methods presented earlier, the circuit taking into account all the resistances in all the directions is realized for a specific asynchronous machine. 
The equivalent circuit for this method is the same as this of the second architecture, except that this time the $\varphi$-axis thermal resistances are taken into account as in Fig. 2.

Taking into account of all the stator and rotor poles increases considerably the total number of TEC elements. So with the variation of slot number the number of nodes varies also. The change of the number of nodes leads to the change of matrixes representing algebraic equations of the differential equation as one presented in (1). The creation of the matrixes with high number of elements is a time consuming process and could be inadmissible if a fast thermal analysis is needed.

$$
\rho_{i} \cdot V_{i}\left(c_{p}\right) \frac{d T_{i}}{d t}=\sum_{j} G_{i j}\left(T_{j}-T_{i}\right)+P_{i}
$$

\section{Experimental validation}

Due to confidentiality reasons the results of comparison of the calculation values and experimental results couldn't be presented in this paper. However, the three architectures are compared to the results issued from the literature. The work of Han et al. [7] from the Korean Institute of Electrical Engineers has been chosen as the reference. The authors consider a $29 \mathrm{~kW}$ @12 krpm asynchronous motor including water cooling jacket.

TABLE I

Design and TeChNiCAL SPECIFICATIONS OF Studied Machine [7]

\begin{tabular}{|c|c|c|}
\hline \multicolumn{3}{|c|}{ Technical characteristics } \\
\hline Power & 29 & $\mathrm{~kW}$ \\
\hline Rated line voltage & 182 & $\mathrm{~V}$ \\
\hline Rated frequency & 400 & $\mathrm{~Hz}$ \\
\hline Rated speed & 12000 & $\mathrm{rpm}$ \\
\hline Water cooling flow & 7 & $1 / \mathrm{min}$ \\
\hline \multicolumn{3}{|c|}{ Design parameters } \\
\hline Stator outer diameter & 145 & $\mathrm{~mm}$ \\
\hline Stator inner diameter & 88 & $\mathrm{~mm}$ \\
\hline Stack length & 150 & $\mathrm{~mm}$ \\
\hline Current density of stator & 8.44 & $\mathrm{~A} / \mathrm{mm} 2$ \\
\hline Flux density of airgap & 0.6 & $\mathrm{~T}$ \\
\hline Max value of stator yoke/tooth flux density & $1.4 / 1.6$ & $\mathrm{~T}$ \\
\hline Electrical steel thickness & 0.2 & $\mathrm{~mm}$ \\
\hline \multicolumn{3}{|c|}{ Thermal conductivities and heat transfer coefficients } \\
\hline Steel thermal conductivity & 33 & $\mathrm{~W} / \mathrm{m} /{ }^{\circ} \mathrm{C}$ \\
\hline Molding of windings thermal conductivity & 1.02 & $\mathrm{~W} / \mathrm{m} /{ }^{\circ} \mathrm{C}$ \\
\hline Slot liner thermal conductivity & 0.14 & $\mathrm{~W} / \mathrm{m} /{ }^{\circ} \mathrm{C}$ \\
\hline Housing thermal conductivity & 168 & $\mathrm{~W} / \mathrm{m} /{ }^{\circ} \mathrm{C}$ \\
\hline Airgap heat transfer coefficient & 128.1 & $\mathrm{~W} / \mathrm{m}^{2} /{ }^{\circ} \mathrm{C}$ \\
\hline Water jacket channel & 6997 & $\mathrm{~W} / \mathrm{m}^{2} /{ }^{\circ} \mathrm{C}$ \\
\hline From end coil to inner air & 133 & $\mathrm{~W} / \mathrm{m}^{2} /{ }^{\circ} \mathrm{C}$ \\
\hline From end ring to inner air & 210 & $\mathrm{~W} / \mathrm{m}^{2} /{ }^{\circ} \mathrm{C}$ \\
\hline From housing to outer air & 8.3 & $\mathrm{~W} / \mathrm{m}^{2} /{ }^{\circ} \mathrm{C}$ \\
\hline \multicolumn{3}{|l|}{ Losses } \\
\hline Stator copper loss & 622 & $\mathrm{~W}$ \\
\hline Rotor copper loss & 453 & $\mathrm{~W}$ \\
\hline Iron loss & 420 & $\mathrm{~W}$ \\
\hline Mechanical loss & 197 & $\mathrm{~W}$ \\
\hline Stray load & 863 & $\mathrm{~W}$ \\
\hline
\end{tabular}

The design characteristics, thermal conductivities of important materials, heat transfer coefficients and loss values in steady state are given in Table I. This information permits to estimate the machine geometry and cooling details.

Particularly, cage dimensions, stator and rotor yoke, as well as stator tooth design were calculated analytically basing on known values of flux densities given in Table I.

Electromagnetic loss distribution was figured out basing on known distribution of flux density values and global value of iron loss inside the machine using Steinmetz loss formulation.

\section{SENSIBILITY STUDY}

Once machine dimensions, as well as electromagnetic and mechanical losses distribution are defined, basing on analytical design methodologies from [8]-[12] and on the data from the Table I, the TEC method could be applied in order to estimate machine thermal behavior in steady state as well as in transient mode.

The first results of proposed TEC architectures compared to the reference values from the literature are presented in the Fig. 5.

As in the reference article [7], the machine winding was divided into three parts: front end winding, winding inside the slot and rear end winding.

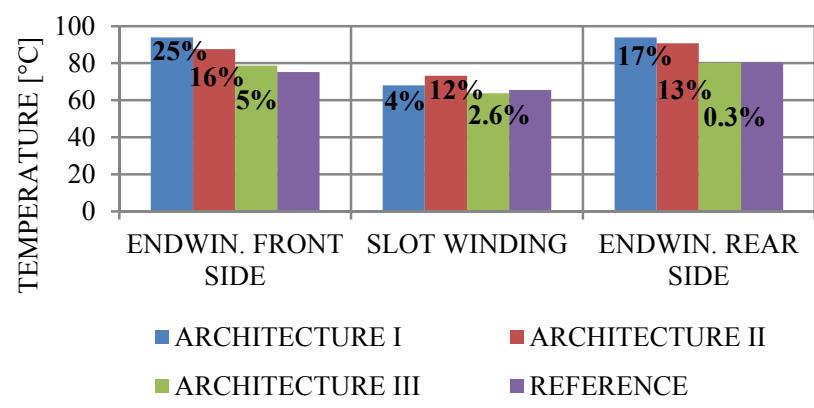

Fig. 5. Comparison of the results of the TEC architectures with the reference values from the literature.

The comparison study has showed that the results of the first, second and third circuit construction methods vary from the reference data upon the average of $20 \%, 14 \%$ and $2.5 \%$ respectively.

The tendency of all the three methods to overestimate the temperatures is positive in point of view of the security requirements of the machine and its environment.

Nevertheless the comparison between experimental data and simulation results has to be treated carefully for the following reasons:

- first of all, some geometry details and some material characteristics that were not presented in [7], have been estimated analytically in order to complete our calculation. So the difference between measured and calculated results could be caused by the inaccuracy of supposed values.

- secondly, the sensors measure only a local temperature in zones where it is usually non-uniform such as end winding, representing a superposition of different phases windings surrounded by air. In other words, the sensors in such regions measure rather a punctual temperature of the air around the end winding, than an average temperature of the 
whole end winding region, which is the case for the nodal method approach.

In order to show the dependence of the models to the accuracy of entry data a sensibility study was carried out. The idea was to vary different entry parameters that are not given in [7] such as machine dimensions, material properties, heat transfer coefficients etc., on order to observe their influence on resulting temperature variation.

As temperature evolution character depends on evolution curves of numerous parameters, such as supply current, voltage, frequency, and as a consequence torque, power and speed evolutions, it is difficult to define the real mission profile corresponding to this temperature evolution character.

As a result it was decided to compare sensibility analysis of each TEC architecture only in steady state, taking into account loss values given in [7].

So given information of losses, thermal conductivities of some materials and some heat transfer coefficients in steady state are taken as absolute values that do not change. While all the missing data, as dimension details, unknown heat transfer coefficients and material characteristics, is evaluated basing on analytical approaches depending on machine parameters. All the estimated data could lead to an uncertainty of the final result.

In this sensibility study it is decided to modify all the variable entry parameters between $\pm 15 \%$ of the first calculated values.

Concerning the main losses, there are only total values given in [7], so the repartition of the losses inside the machine parts has to be supposed and could also provoke an inaccuracy.

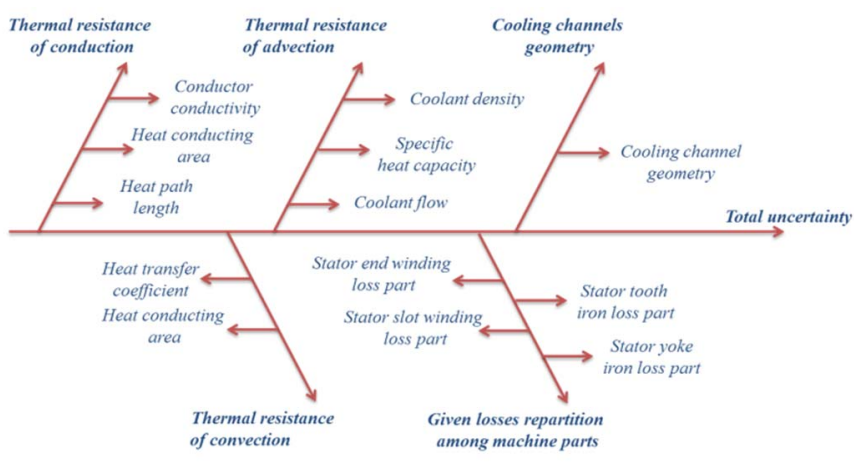

Fig. 6. Ishikawa diagram of the main parameters influencing the final result.

All the potential parameters that could influence the final result are presented on the Ishikawa diagram in Fig. 6.

\section{RESULTS AND DISCUSSION}

\section{A. Influence of dimensions uncertainty}

The set of thermal resistances/conductances depends intensely on dimensions of the machine.

The results of some dimensions variation, such as stator and rotor teeth height and width are presented in Fig. 7.

The error bars represent the maximal and minimal deviation of temperatures in all the three zones and for all the three TEC architectures about the temperature values obtained above.

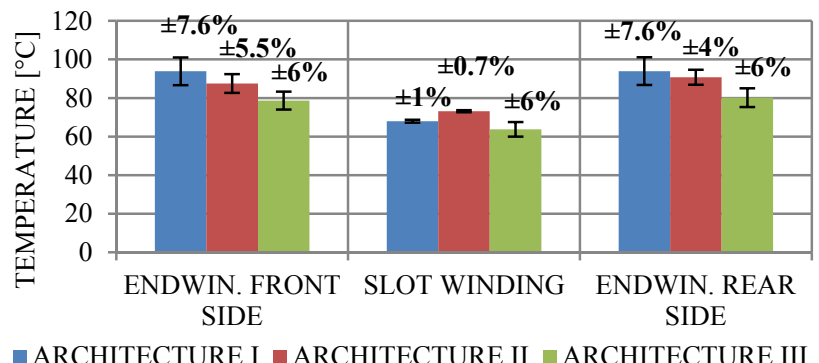

Fig. 7. Results deviation of the models caused by variation of some machine dimensions.

It could be seen that the average deviation caused by dimensions variation between $\pm 15 \%$ of the analytically estimated values for all the three models is upon the average of $\pm 7 \%$ around the temperatures obtained initially.

It is interesting that only third circuit architecture has a uniform response of all the parts. The second model, neglecting the heat flux in orthoradial direction between slots winding and teeth, overestimates the winding temperature inside the slots and varies lightly with the slot dimensions variation, which could be explained by the fact that the modified values do not have a significant impact on the contact thermal resistance between slots and stator yoke.

\section{B. Influence of heat transfer coefficients variation}

The thermal characteristics of machine materials have an important influence on its thermal analysis.

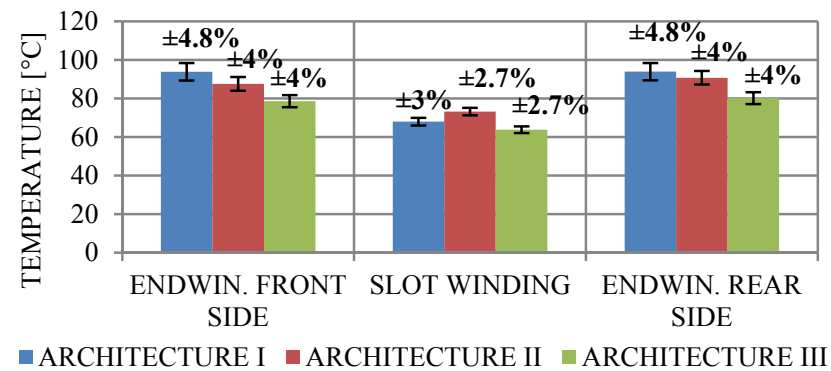

Fig. 8. Results deviation of the models caused by variation of some heat transfer coefficients.

Despite the fact that heat transfer coefficients in the most important machine parts are given in [7], the variation these parameters inside the machine for about $\pm 15 \%$, the final temperature results deviate for about $\pm 4 \%$ around the value calculated initially for all the three models.

\section{Influence of material thermal properties}

Thermal conductivities serving the evaluation of thermal resistances matrix has an important role in thermal analysis of electrical machines.

The sensibility study has shown that inaccuracy of thermal conductivity values of about $\pm 15 \%$ could provoke an uncertainty of calculated temperatures not exceeding $\pm 3.5 \%$ 
for all the three architectures.

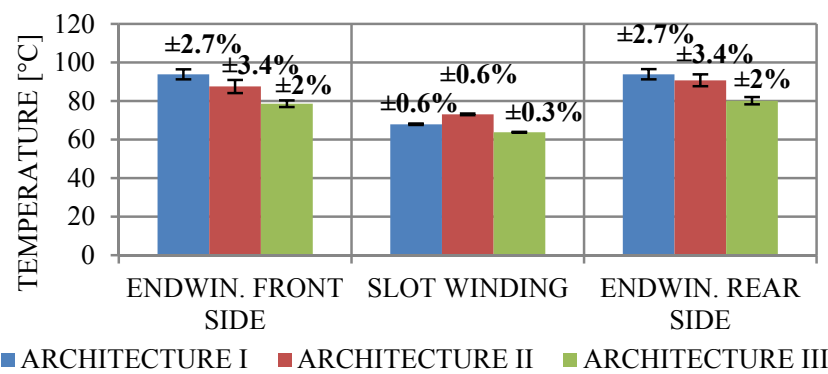

Fig. 9. Results deviation of the models caused by variation of some materials thermal conductivities.

Such a moderate influence of thermal conductivities on the final results in our study could be explained by the fact that thermal characteristics for the most important machine part are given in [7] and were not modified during the study.

\section{Influence of stator copper loss distribution}

As it was mentioned above the loss values given in [7] represent the total loss values and there is no information about loss distribution among the machine parts.

Particularly, for the stator copper loss, the first thermal results were obtained by considering $25 \%, 50 \%$ and $25 \%$ of the total copper loss for stator front end winding, winding inside the slots and rear side end winding parts respectively.

Then these values were modified for $\pm 15 \%$ of the first supposition. The results of this study are presented in Fig. 10 and show that loss distribution among the winding plays an important role in thermal analysis of electrical machines. For the first and second models the uncertainty of calculated temperatures inside the stator winding could achieve $\pm 13 \%$.

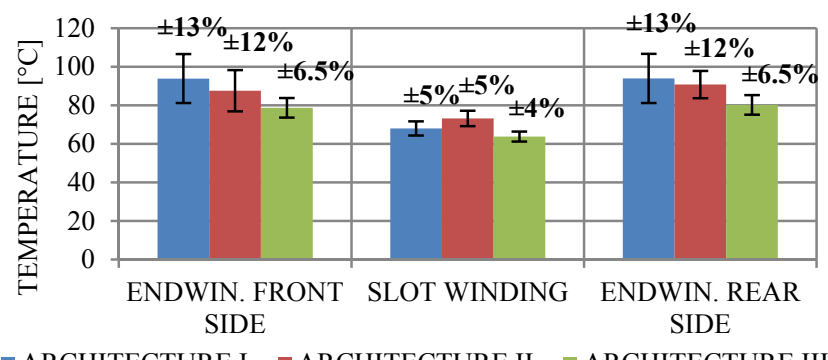

Fig. 10. Results deviation of the models caused by variation of copper loss distribution inside the winding.

\section{E. Influence of stator iron loss distribution}

The uncertainty of iron loss repartition, on the other hand, has not such a considerable influence on the thermal analysis of the machine.

For the first analysis the iron loss was halved between stator teeth and stator yoke. Within the sensibility study this repartition was modified between $\pm 15 \%$, which did not provoke any considerable temperature deviation.

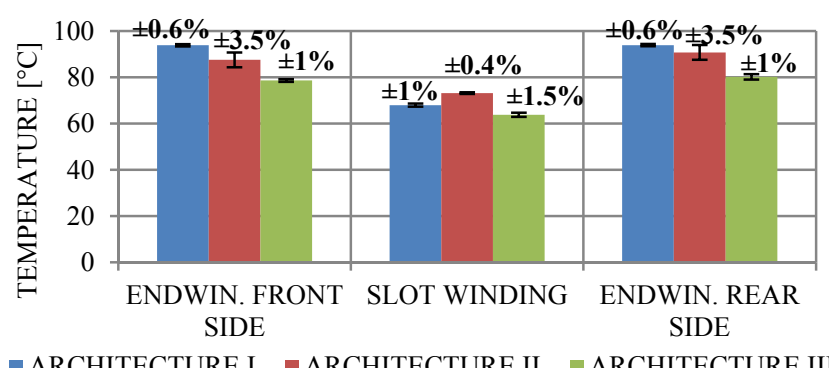

Fig. 11. Results deviation of the models caused by variation of iron loss distribution inside stator core.

\section{CONCLUSION}

In this article, three TEC architectures were compared to experimental test results from the literature in order to define one that could be implemented in a generalized low time cost numerical tool. The study was carried out on a $29 \mathrm{~kW}$ high speed asynchronous machine.

Aiming to study the difference between calculated values and experimental test results, a sensibility analysis was carried out.

The influence of uncertainties of the most important parameters, such as design and geometry details, some materials thermal characteristics, heat source distribution, the non-uniform temperature distribution etc., was examined for the three TEC architectures.

The list of the studied parameters from the most to the less influencing the thermal analysis is shown in Fig. 12.

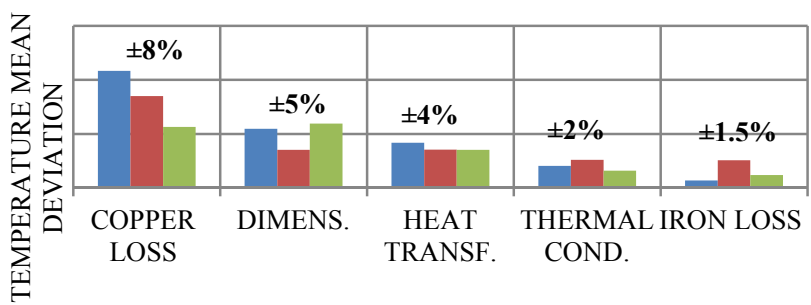

ARCHITECTURE I $\square$ ARCHITECTURE II $\square$ ARCHITECTURE III

Fig. 12. The mean deviation of temperature results for three TEC architectures.

View an important deviation of thermal models with a deviation of some entry parameters, it could be concluded that all the three TEC architectures could be enough precise if all the entry data are known and accurate.

As the third architecture could not be selected for an application in a generalized thermal model because of its significant time cost of node architecture preparation, the choice has to be made between the first and the second TEC.

According the sensibility study, it appears that the thermal equivalent circuit architecture neglecting the heat flux in orthoradial direction between slots and teeth matches better the reference temperature and on the condition of an adequate adjustment coefficient choice, it could be a good compromise solution for a generalized thermal model of helicopter electric propulsion system. This TEC construction 
principle permits to keep a better time cost of the model as well as an acceptable precision.

\section{REFERENCES}

[1] John Blandino, "Overview of Electric Propulsion Research in U.S. Academia", AIAA-2003-4442 39th AIAA Joint Propulsion Conference, July 2003.

[2] K-S Kim, B-H Lee, J-P Hong, "Improvement of Thermal Equivalent Circuit Network and Prediction on Heat Characteristic of Motor by Calculation of Convection Heat Transfer Coefficient", Dept. of Automotive Eng., Hanyang Univ., Seoul, South Korea, IEEE, 2012

[3] K-S Kim, H-J Kim, J-P Hong, "Thermal equivalent circuit network for outer rotor type motors" Power Electronics, Machines and Drives (PEMD 2014), 7th IET International Conference on April 2014, IET

[4] G. Henneberger, K. B. Yahia, M. Schmitz, "Calculation and identification of a thermal equivalent circuit of a water cooled induction motor for electric vehicle applications", IET, Electrical Machines and Drives, pp. 6-10, no 412, Sep. 1995

[5] Christian Kral, Anton Haumer, Matthias Haigis, Hermann Lang, "Comparison of a CFD Analysis and a Thermal Equivalent Circuit Model of a TEFC Induction Machine With Measurements", IEEE Trans. Energy Convers., vol. 24, pp. 809 - 818, Nov. 2009

[6] M. Necato Ozisik, "Finite Difference Method in Heat Transfer", Mechanical and Aerospace Engineering Department North Carolina State University, CRC Press, vol. 432, 1994.

[7] P-W. Han, J-H. Choi, D-J. Kim, Y-D. Chun, D-J. Bang, "Thermal Analysis of High Speed Induction Motor by Using Lumped-Circuit Parameters", Journal of Electrical Engineering \& Technology, vol. 10, pp. 709-714, 2015.

[8] A.K. Sawhney, "Electrical Machine Design", Dhanpat Rai \& Co. (P) Ltd., vol. 1128, 2014.

[9] A. Bousbaine, "An Investigation into the Thermal Modeling of Induction Motors", Thesis submitted to the University of Sheffield for the Degree of Doctor of Philosophy, vol. 162, 1993.

[10] J. Pyrhonen, T. Jokinen, V. Hrabovcova, "Design of Rotating Machines", John Wiley \& Sons, Ltd. ISBN: 978-0-470-69516-6, vol. 502, 2008

[11] M. Jaaskelainen, "Determination of coefficients of thermal convection in a high speed electrical machine", Thesis submitted to the Helsinki University of Technology for the Degree of Master of Science in Technology, vol. 45, 2009.

[12] O.D. Goldberg, "Design of electrical machines", Vysshaya shkola: Moscow, ISBN 5-06-005673-2, Vol. 426, 1984.

\section{BIOGRAPHIES}

Shinara Utegenova was born in Kazakhstan, in 1988. She received the B.Sc. in Engineering Science from the Peoples Friendship University of Russia in Moscow. In 2013, she received the M.Sc. degree in Engineering Science in 2013 from the University of Pierre and Marie Curie in Paris.
In September 2014, she started her Ph.D. research at FEMTO-ST Institute (UMR CNRS 6174) / ENERGY Department, University of Bourgogne Franche-Comte (UBFC), in collaboration with Airbus Helicopters.

Her research interests include thermal modeling, loss analysis, and design of cooling system, particularly in aerospace hybridization.

Raynal Glises is an Associate Professor at the University of Bourgogne Franche-Comté. He received the Ph.D. degree in Engineering Sciences from the University of Franche-Comté in 1994. He is currently the head of the THERMIE Team of the ENERGY Department, FEMTO-ST Institute. His research interests are focused on the field of the thermal management of electric motors, including the thermal modeling by nodal method.

Philippe Desevaux is a Full Professor at the University of Bourgogne Franche-Comté. He received the Ph.D. degree in Engineering Sciences from the University of Franche-Comté in 1994. His research interests are concentrated in the field of thermal and fluid sciences, including the thermal management of electric motors and the design of cooling systems.

Frédéric Dubas was born in Vesoul, France, in 1978. He received the Master Degree from the University of Franche-Comté (UFC), Belfort, France, in 2002, and the Ph.D. degree from the UFC, in 2006, with a focus on the design and the optimization of high-speed surface-mounted permanent-magnet (SMPM) motors for the drive of a fuel cell aircompressor.

He is currently an Associate Professor at the ENERGY Department, FEMTO-ST Institute, UFC where he is the Head of the "Unconventional Thermal and Electrical Machines" Team. He works with ALSTOM Transports, Ornans, France, and RENAULT Technocenter, Guyancourt, France, where he is involved in the modeling, design and optimization of electrical systems and, particularly, induction and PM synchronous (radial and/or axial flux) machines, creative problem solving, and electrical propulsion/traction. He has authored over 50 refereed publications and a patent about the manufacturing of axial-flux PM machines with fluxfocusing.

Dr. Dubas received the Prize Paper Awards in the IEEE Conference Vehicle Power and Propulsion (VPPC) in 2005.

Damien Mariotto was born in Aix-en-Provence, France, in 1982. He was graduated in 2007 from two Engineering schools: SUPELEC, Paris, France, and Ecole Nationale Supérieure d'Arts et Metiers, Paris, Aix-enProvence. $\mathrm{He}$ is currently working at AIRBUS HELICOPTERS at Marignane as an electrical systems Engineer and more precisely in the power machine field within Research and Development activities frame.

Bertrand Truffart is Dr-Engineer of Polytech'Nantes (1991) and University of Nantes (1996). His Ph.D. thesis was focused on Inverse Heat Transfer problems. He is currently working at AIRBUS HELICOPTERS at Marignane as thermal engineer, more precisely in the frame of Method and Tools, Research and Development activities. 